\title{
Phase engineering of Mo-V oxides molecular sieves for zinc-ion batteries
}

\author{
Gan $\mathrm{Qu}^{2 \dagger}$, Chuntian $\mathrm{Qiu}^{1 \dagger}$, Jun Wang ${ }^{1}$, Jiewen Tan ${ }^{1}$, Shuangfeng Jia ${ }^{4}$, Zhesheng Chen ${ }^{5}$, \\ Jean-Pascal Rueff ${ }^{5,6}$, Wesley Guangyuan Zheng ${ }^{3}$, Chenliang $\mathrm{Su}^{1}$ and Bingbing Tian ${ }^{1^{*}}$
}

\begin{abstract}
With the ever-increasing demands of grid-scale energy storage, aqueous zinc-ion batteries (ZIBs) have garnered increasing attention around the world. However, limited $\mathrm{Zn}^{2+}$ host materials have hindered the commercialization of ZIBs. Hence, Mo-V oxides with different phase structures (orth-, tri-, and tetra-MoVO) were precisely constructed to develop phase-dependent Mo- $\mathrm{V}$ oxide cathodes for $\mathrm{Zn}^{2+}$ storage in ZIBs. The open frameworks and varied tunnel structures formed a favorable alternative for achieving suitable $\mathrm{Zn}^{2+}$ diffusion kinetics. With optimized phase engineering, the high specific capacity of approximately $400 \mathrm{~mA} \mathrm{~h} \mathrm{~g}^{-1}$ and excellent cyclic stability of 1000 cycles were achieved with orthMoVO as the cathode. The large amount of six- and sevenmember rings in the orth-MoVO phase, which allow for alternative $\mathrm{Zn}^{2+}$ insertion, play a vital role in hosting $\mathrm{Zn}^{2+}$ ions reversibly. The proposed phase engineering strategy provides a new approach toward cathode design in ZIBs.
\end{abstract}

Keywords: zinc-ion batteries, phase engineering, molybdenum oxides, vanadium oxides

\section{INTRODUCTION}

Nowadays, the energy crisis and environmental pollution are the most critical global problems. Although numerous clean and renewable energy sources have been successfully investigated, these energy sources are severely limited by time and space [15]. Therefore, an efficient large-scale energy storage system is necessitated [6-10]. Aqueous zinc-ion batteries (ZIBs) are ideal candidates, owing to their low cost and environmental efficiency [11-14]. Zinc is abundant on earth, and $\mathrm{Zn}$ metal is easy to exploit, transfer, and store [15-17]. Additionally, it exhibits high theoretical capacities of $819 \mathrm{~mA} \mathrm{~h} \mathrm{~g}^{-1}$ and $5851 \mathrm{~mA} \mathrm{~h} \mathrm{~mL}^{-1}$ [18]. The redox potential for $\mathrm{Zn} / \mathrm{Zn}^{2+}$ is as low as $-0.76 \mathrm{~V}$ versus the standard hydrogen electrode, when the overpotential for the hydrogen evolution reaction is very high [19-22]. The twoelectron transfer reaction renders high energy density feasible for ZIBs [23-26]. Moreover, the neutral electrolyte provides high conductivity, alleviates the zinc loss, and eliminates the envir- onmental impact. Regardless of these advantages, developing suitable cathodes in ZIBs is still an enormous challenge [27-30]. In fact, most cathode materials often undergo a structural collapse and severe degradation [13,31]. Therefore, innovations with regard to new cathode materials with high energy density, which are capable of preventing structural collapse and degradation, are urgently needed [25]. Mo-V-based oxides with a solid open framework, tuneable phase, tunnel structures, and improved conductivity owing to the intervalence electron transfer between Mo and V, are potential candidates for $\mathrm{Zn}^{2+}$ storage in ZIBs [32].

Phase engineering is a promising strategy for structural modulation in developing advanced cathode materials [33]. The crystal phase with a defined arrangement and organization of atoms and/or building blocks significantly influences the physical and chemical properties [34]. Thus, subtle structural changes may generate different properties. For instance, the conductivities and structural stability are closely associated with the atomic arrangements [35]. The organization of building blocks dictates the thermodynamic and kinetic processes, as the adsorption and activation of reactant molecules significantly depend on the atomic configurations. These phase engineering guidelines contribute toward the designing and synthesizing of the desired phase-dependent cathodes for ZIBs [36]. Moreover, successful phase engineering approaches may allow the further investigation of the charge/discharge mechanism and structureactivity relationship for fine-tuning the electrochemical performance of ZIBs [37].

In this study, Mo-V oxides with diverse phase structures (orth-, tri-, and tetra-MoVO) were obtained, which comprised corner-sharing $\left[\mathrm{MO}_{6}\right]$ octahedral and pentagonal $\left[(\mathrm{M}) \mathrm{M}_{5} \mathrm{O}_{27}\right]$ to construct three-, four-, five-, six-, and seven-member rings. The open framework and varied phase structures were favourable to the $\mathrm{Zn}^{2+}$ diffusion kinetics. Consequently, high specific capacity of $\left(400 \mathrm{~mA} \mathrm{~h}^{-1}\right)$ and excellent cyclic stability of 1000 cycles were achieved with orth-MoVO as the cathode. The $\mathrm{Zn}^{2+}$ insertion/extraction processes were analyzed in detail to elucidate the energy storage mechanism. Compared with tri- and tetra-MoVO, a large amount of six- and seven-member rings in

\footnotetext{
${ }^{1}$ International Collaborative Laboratory of 2D Materials for Optoelectronics Science and Technology of Ministry of Education, Institute of Microscale Optoelectronics, Shenzhen University, Shenzhen 518060, China

${ }^{2}$ College of Materials Science and Engineering, Zhengzhou University, Zhengzhou 450001, China

${ }^{3}$ Department of Chemical and Biomolecular Engineering, National University of Singapore, 10 Kent Ridge Crescent, Singapore 119260, Singapore

${ }^{4}$ School of Physics and Technology, Center for Electron Microscopy, MOE Key Laboratory of Artificial Micro- and Nano-structures, and Institute for Advanced Studies, Wuhan University, Wuhan 430072, China

${ }^{5}$ Société Civile Synchrotron SOLEIL, L’Ormedes Merisiers, Saint-Aubin, BP48, Gif-sur-Yvette 91192, France

${ }^{6}$ Laboratoire de Chimie Physique-Matière et Rayonnement, LCPMR, Sorbonne Université, CNRS, Paris F-75005, France

$\dagger$ These authors contributed equally to this work.

* Corresponding author (email: tianbb2011@szu.edu.cn)
} 
orth-MoVO play a vital role in hosting the $\mathrm{Zn}^{2+}$ reversibly.

Both Mo and V can form various polyoxometalates, which act as the building blocks of supramolecular compounds and constituted mixed polyoxometalates, thus resulting in a stabilized molecular architecture and exhibiting unique physical and chemical properties [27,38-42]. The phases and bulk frameworks can be tuned by controlling the arrangement and organization of the Mo- and V-blocks. Thus, the modified metal-oxygen bond, pore size, and affinity in the molecules may have contributed toward achieving versatile performance. Therefore, it is possible to employ and engineer Mo- $\mathrm{V}$ oxides to reversibly host $\mathrm{Zn}^{2+}$ by adjusting the building blocks and designing suitable phase and tunnel structures.

\section{EXPERIMENTAL SECTION}

\section{Synthesis of orth-MoVO, tri-MoVO, and tetra-MoVo}

Typically, $15 \mathrm{mmol}$ of $\left(\mathrm{NH}_{4}\right)_{6} \mathrm{Mo}_{7} \mathrm{O}_{24} \cdot 4 \mathrm{H}_{2} \mathrm{O}$ and $3.75 \mathrm{mmol}$ of $\mathrm{VOSO}_{4}$ were dissolved in $80 \mathrm{~mL}$ deionized water and poured into a $100-\mathrm{mL}$ Teflon-lined stainless steel autoclave with Teflon thin sheet. Then, the solution was purged with nitrogen for $10 \mathrm{~min}$ and heated to $175^{\circ} \mathrm{C}$ for $48 \mathrm{~h}$. The obtained grey product was purified with $0.4 \mathrm{~mol} \mathrm{~L}^{-1}$ oxalic acid for $30 \mathrm{~min}$ at $70^{\circ} \mathrm{C}$. After filtration, washing, and drying, the orth-MoVO was obtained. The as-prepared orth-MoVO was firstly heated to $400^{\circ} \mathrm{C}$ for $2 \mathrm{~h}$ in air, and then annealed at $873 \mathrm{~K}$ for $4 \mathrm{~h}$ in nitrogen to produce tetra-MoVO. For the synthesis of triMoVO, the $\mathrm{pH}$ value of the solution was mediated to 2.2 with $2 \mathrm{~mol} \mathrm{~L}^{-1}$ sulphuric acid, and the reaction condition was adjusted to $175^{\circ} \mathrm{C}$ and maintained for $20 \mathrm{~h}$ while the other conditions were same as orth-MoVO synthesis. The orth-MoVO and triMoVO were annealed at $400^{\circ} \mathrm{C}$ for $4 \mathrm{~h}$ in air before use.

\section{Electrochemical measurements}

The electrochemical performance was evaluated with a CR2016 coin-type cell. The active material, acetylene black, and polyvinylidene fluoride (PVDF) were mixed with a mass ratio of 8:1:1 in 1-methyl-2-pyrrolidinone (NMP). After being stirred for $24 \mathrm{~h}$, the slurry was obtained and coated on Ti foil. Subsequently, the prepared sample, Celgard 3501 membrane, and $\mathrm{Zn}$ foil acted as the cathode, separator, and anode, respectively. The electrolyte was $2 \mathrm{~mol} \mathrm{~L}^{-1}$ aqueous $\mathrm{Zn}\left(\mathrm{CF}_{3} \mathrm{SO}_{3}\right)_{2}$. The loading mass was approximately $1.2 \mathrm{mg} \mathrm{cm}^{-2}$. The cyclic voltammetry $(\mathrm{CV})$ measurement was conducted at a scan rate of $0.2 \mathrm{mV} \mathrm{s}^{-1}$ with an electrochemical station from Princeton Applied Research. Galvanostatic charge-discharge (GCD) and long-term stability tests were carried out using a BTS 4000 (NEWARE) battery testing system.

\section{Characterizations}

The morphologies of all the samples were acquired by using field-emission scanning electron microscope (SEM, JSM-6700F, JEOL), transmission electron microscope (TEM, JEM-F200 and JEM-ARM300F, JEOL) and energy dispersive X-ray spectroscope (EDS). The ex-situ and in-situ X-ray diffraction (XRD) patterns were measured using a Rigaku Ultima IV diffractometer with $\mathrm{Cu}$ Ka radiation. The in-situ Fourier transformed infrared (FTIR) spectra were obtained using a Bruker Vertex 70v spectrometer. The X-ray photoelectron spectroscopy (XPS) spectra were obtained using VG Multilab 2000 (Thermo Fisher Scientific) with monochromatized $\mathrm{Al} \mathrm{Ka}$ radiation. The metallic atom ratio for the sample was obtained using inductively coupled plasma-atomic emission spectroscopy (ICP-AES, ICPE-9000, Shimadzu). The ultraviolet-visible (UV-vis) spectroscopy diffuse reflectance spectra were characterized by a Cary 5000 UV-visnear infrared (NIR) (Agilent) spectrometer. The K-edge absorption spectra of $\mathrm{V}, \mathrm{Mo}$, and $\mathrm{Zn}$ were measured at room temperature with a sampling step of $3.0 \mathrm{eV}$ for extended X-ray absorption fine structure (EXAFS).

\section{Computational details}

The density functional theory (DFT) with the Perdew-BurkeErnzerbof (PBE) form of generalized gradient approximation functional (GGA) was used in this work [43]. The Vienna $a b$ initio simulation package (VASP) was employed [44-48]. The plane wave energy cutoff was set as $400 \mathrm{eV}$. The electron occupancy is described by the Fermi scheme with an energy smearing of $0.1 \mathrm{eV}$. The first Brillouin zone was sampled in the Monkhorst-Pack grid with the $2 \times 2 \times 1 \mathrm{k}$-point mesh. The energy (converged to $1.0 \times 10^{-6} \mathrm{eV}$ atom $^{-1}$ ) and force (converged to $0.01 \mathrm{eV} \AA^{-1}$ ) were set as the convergence criterion for geometry optimization. The spin polarization was considered in all calculation. To consider the ability to accommodate $\mathrm{Zn}$ ions, the formation energy of $\mathrm{Zn}$ ions ( $\Delta E_{\mathrm{f}}$, shown in the following) embedded into the three investigated systems are employed.

$\Delta E_{\mathrm{f}}=E_{\mathrm{Sys}+(x+1) \mathrm{Zn}}-E_{\mathrm{Sys}+x \mathrm{Zn}}-\mu_{\mathrm{Zn}},(x=0-2)$,

where $\Delta E_{\text {Sys } x Z \mathrm{n}}$ and $\Delta E_{\mathrm{Sys}+(x+1) \mathrm{Zn}}$ are the total energies of the systems with $x \mathrm{Zn}$ and $(x+1) \mathrm{Zn}$, respectively. $\mu_{\mathrm{Zn}}$ is the chemical potential of $\mathrm{Zn}$, which is referred to the $\mathrm{Zn}$ bulk. The positive (negative) value of $\Delta E_{\mathrm{f}}$ means the process of $\mathrm{Zn}$ ion embedding into the systems is favorable (unfavorable) in energy. And the more positive of $\Delta E_{\mathrm{f}}$, the harder for the $\mathrm{Zn}$ ion embedding.

\section{RESULTS AND DISCUSSION}

By regulating the building units, a series of defined phases (orth-, tri-, and tetra-MoVO) can be fabricated and applied in ZIBs. Those Mo-V oxides consist of the pentagonal polyoxomolybdate $\left[\mathrm{Mo}_{6} \mathrm{O}_{21}\right]$ with a central $\mathrm{MO}_{7}(\mathrm{M}=\mathrm{Mo}, \mathrm{V})$ pentagonal bipyramidal unit and edge-sharing $\mathrm{MO}_{6}$ octahedral [49-51]. The existing various continuous channels in the [001] direction could give a positive effect on the $\mathrm{Zn}^{2+}$ diffusion (insets of Fig. 1a, d, and g). The variable tunnel structures endow the three oxides with the open channel frameworks, resulting in varied diffusion kinetics of $\mathrm{Zn}^{2+}$. Compared with the tri-MoVO phase, the orth-MoVO structure possesses more six- and sevenmember rings in the [001] direction, while the tetra-MoVO only comprises four- and five-member rings. Powder XRD patterns were employed to characterize the crystalline structure (Fig. 1a, $\mathrm{d}$, and g), in agreement with previously reported data [52]. The well-defined XRD patterns indicate high crystallinity. The highresolution TEM (HR-TEM) images in Fig. 1b, e, and h show the lattice spaces of the three samples, and the morphological and elemental features are shown in Fig. 1c, f, and i. The TEM images of the three samples show a $1 \mathrm{D}$ rod-like shape, with a diameter of approximately $200 \mathrm{~nm}$. Moreover, the crystallographic growth occurred along the [001] direction. The EDS mappings reveal that the distributions of the $\mathrm{Mo}, \mathrm{V}$, and $\mathrm{O}$ elements are completely consistent with the TEM images of the three samples. As shown in Fig. S1, the UV-vis-NIR diffuse reflectance spectra of the orth-, tri-, and tetra-MoVO exhibit an apparent absorption in the visible light region, owing to the 

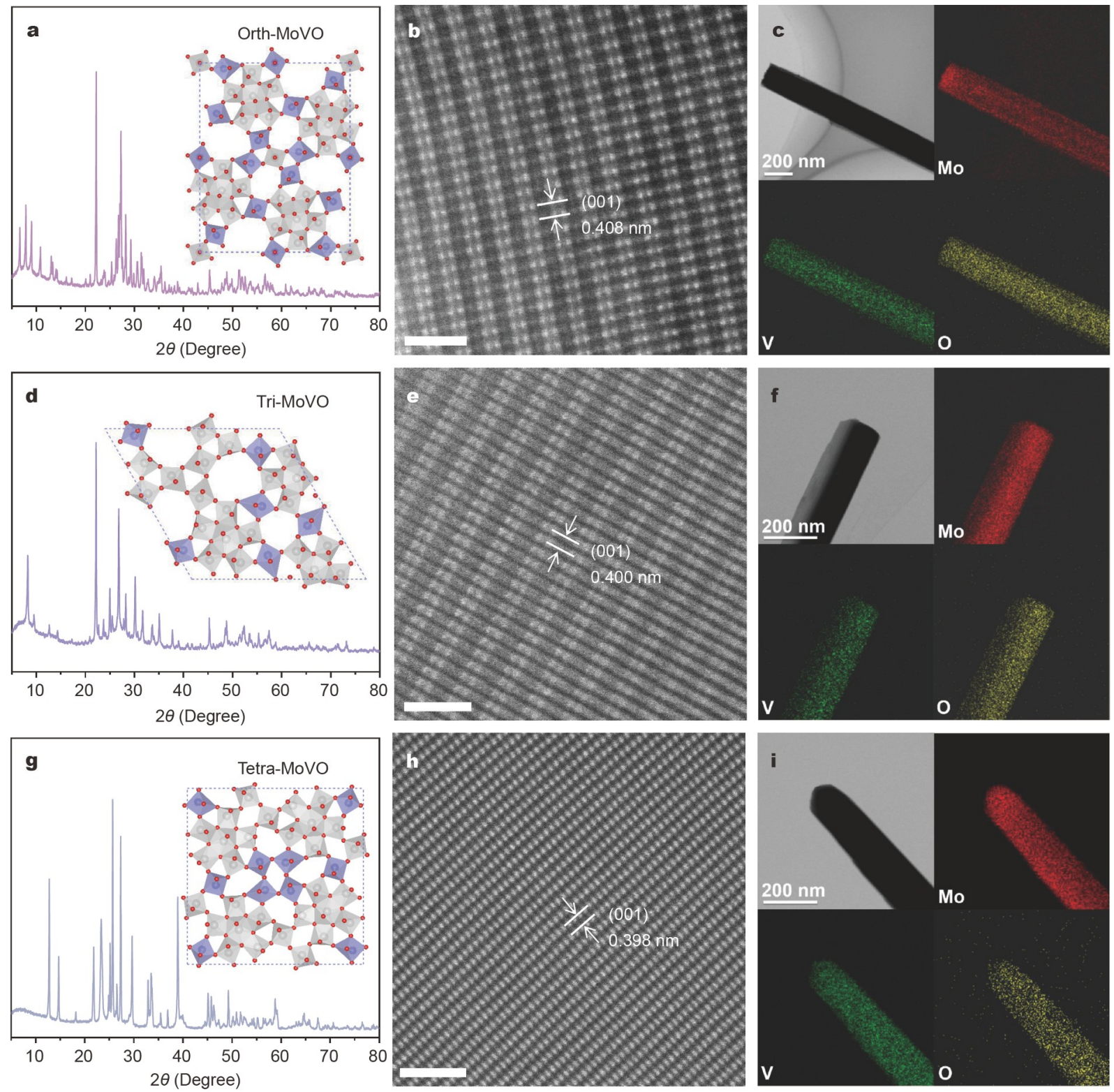

Figure 1 XRD patterns, TEM, and EDS mapping images of (a, b, c) orth-, (d, e, f) tri- and (g, h, i) tetra-MoVO. Red: Mo; Green: V; Yellow: O. Scale bars in (b, e, h) are $2 \mathrm{~nm}$.

electron transfer between Mo and V. The unique band structure indicates improved conductivity, which is favorable to the electrochemical process.

To estimate the $\mathrm{Zn}^{2+}$ storage ability of the as-prepared Mo-V oxides, the CR2016-type cell was assembled with Mo-V oxides as the cathodes and $\mathrm{Zn}$ foil discs as the anodes. The electrolyte was $2 \mathrm{~mol} \mathrm{~L}^{-1}$ aqueous $\mathrm{Zn}\left(\mathrm{CF}_{3} \mathrm{SO}_{3}\right)_{2}$ solution. Fig. 2 shows the $\mathrm{CV}$ and GCD curves of the orth-, tri-, and tetra-MoVO cathodes. Obviously, the orth-MoVO exhibited a $\mathrm{Zn}^{2+}$ insertion potential of approximately $0.55 \mathrm{~V}$ and a multistep extraction potential of approximately $0.55,0.70$, and $0.80 \mathrm{~V}$ (Fig. $2 \mathrm{a}, \mathrm{d}$ ). In the subsequent $2^{\text {nd }}$ and $3^{\text {rd }}$ cycles, the $\mathrm{Zn}^{2+}$ insertion processes became facile and the CV curves exhibited good reversible properties. In Fig. 2b, the tri-MoVO exhibited similar CV as the orth-MoVO and an additional $\mathrm{Zn}^{2+}$ insertion potential at $0.30 \mathrm{~V}$. However, the tetra-MoVO exhibited one pair of redox peaks (Fig. 2c), which suffered from severe irreversibility in the subsequent $2^{\text {nd }}$ and $3^{\text {rd }}$ cycles. As shown in Fig. $2 d-f$, the orth-MoVO had a specific capacity of approximately $400 \mathrm{~mA} \mathrm{hg}^{-1}$ at $0.1 \mathrm{Ag}^{-1}$ owing to the large amount of six- and seven-member ring tunnels, while the tri- and tetra-MoVO delivered less than $200 \mathrm{~mA} \mathrm{~h} \mathrm{~g}^{-1}$. Additionally, the specific capacity of the orthMoVO was approximately without attenuation during the first three cycles. Hence, the four- and five-member ring tunnels of the tetra-MoVO contribute toward slow diffusion kinetics, which lead to a lower specific capacity. The poor reversibility of the tetra-MoVO is caused by the large charge repulsion force of $\mathrm{Zn}^{2+}$ and the narrow tunnels. Thus, the orth-MoVO is a more suitable cathode for ZIBs. The galvanostatic intermittent titration technique (GITT) measurements show that the $\mathrm{Zn}^{2+}$ diffusion coefficient for the orth-MoVO ranges from $10^{-8}$ to $10^{-9} \mathrm{~cm}^{2} \mathrm{~s}^{-1}$ order of magnitude, revealing the fast ion migration (Fig. S2).

The exact atomic ratio and electrochemical performances of 

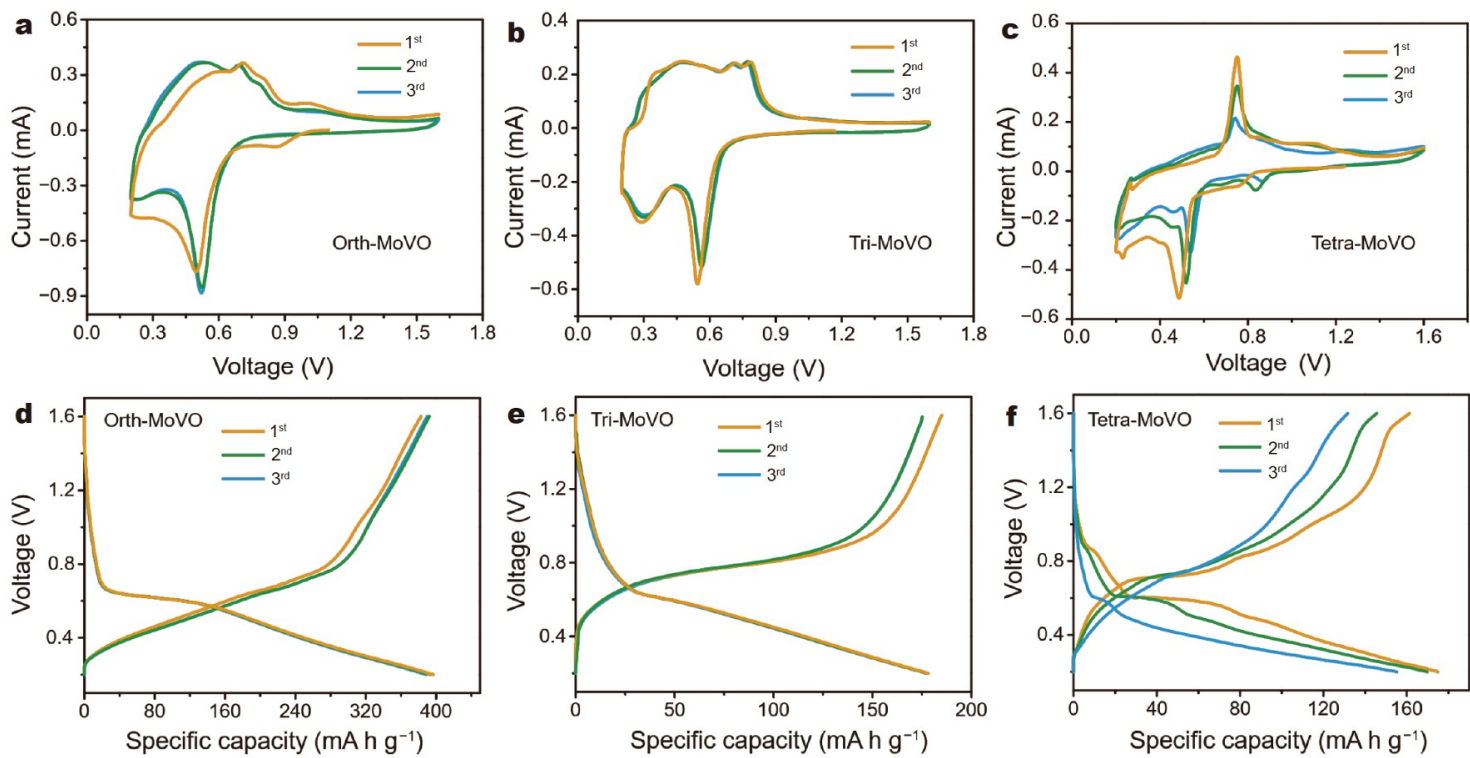

Specific capacity $\left(\mathrm{mA} \mathrm{h} \mathrm{g} \mathrm{g}^{-1}\right)$
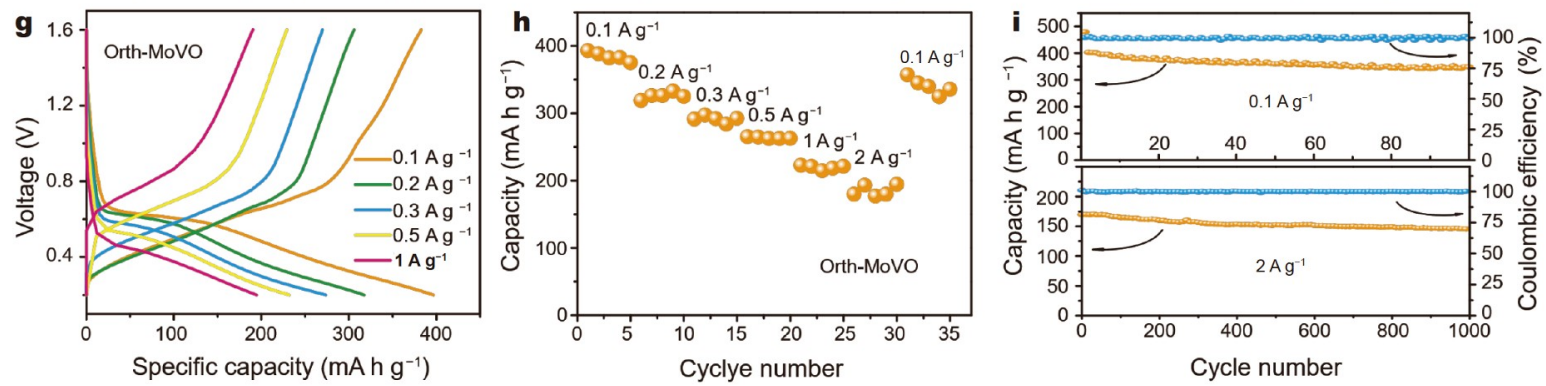

Figure 2 (a-c) CV plots at $0.2 \mathrm{mV} \mathrm{s}^{-1}$ and (d-f) the first three GCD curves at $0.1 \mathrm{~A} \mathrm{~g}^{-1}$ of orth-, tri- and tetra-MoVO; (g) GCD curves of orth-MoVO at current densities from 0.1 to $2 \mathrm{Ag}^{-1}$; (h) rate capability of orth-MoVO; (i) long-term cycling stabilities of orth-MoVO at 0.1 and at $2 \mathrm{Ag}^{-1}$.

the orth-MoVO were investigated in detail to clarify the $\mathrm{Zn}^{2+}$ storage mechanism. ICP-AES, thermogrametric (TG) and in-situ $\mathrm{XRD}$ analyses revealed the molecular formula of the orth-MoVO can be defined as $\mathrm{Mo}_{2.55} \mathrm{VO}_{9.43}$ (Figs S3 and S4). The specific capacity gradually decreased from $400 \mathrm{~mA} \mathrm{~h} \mathrm{~g}^{-1}$ at $0.1 \mathrm{Ag}^{-1}$ to $170 \mathrm{~mA} \mathrm{~h} \mathrm{~g}^{-1}$ at $2 \mathrm{~A} \mathrm{~g}^{-1}$ (Fig. 2g, h). The orth-MoVO delivered a specific capacity of $347 \mathrm{~mA} \mathrm{~h} \mathrm{~g}^{-1}$ at $0.1 \mathrm{~A} \mathrm{~g}^{-1}$ after 100 cycles (Fig. 2i). Additionally, the specific capacity reached $145 \mathrm{~mA} \mathrm{~h} \mathrm{~g}^{-1}$ at $2 \mathrm{Ag}^{-1}$ after 1000 cycles. However, the rate capabilities were quite poor for the tri- and tetra-MoVO, and both of them underwent severe capacity degradation at $0.1 \mathrm{~A} \mathrm{~g}^{-1}$ (Fig. S5). The discharge plot was divided into two parts for the GCD curves. One part was a platform at $0.65 \mathrm{~V}$, while the other part was an inclined line from 0.55 to $0.20 \mathrm{~V}$. Fig. S6 shows the GCD plots at $0.1 \mathrm{Ag}^{-1}$ with $\mathrm{Zn}\left(\mathrm{CF}_{3} \mathrm{SO}_{3}\right)_{2}$ dissolved in acetonitrile. The discharge plots deliver the same specific capacity in acetonitrile, compared with that in water. The $2^{\text {nd }}$ discharge plot illustrates that the extraction of $\mathrm{Zn}^{2+}$ is incomplete. The residual $\mathrm{Zn}^{2+}$ may have acted as pillars for expanding and stabilizing the crystalline orth-MoVO structure, which facilitates the subsequent insertion process. In addition, the discharge plots for orth-MoVO rule out the intercalation of $\mathrm{H}^{+}$in aqueous electrolyte. As shown in Figs S7-S9, the capacitor-type contribution increases from $59.0 \%$ to $95.8 \%$ when the scan rate increases from 0.2 to $5 \mathrm{mV} \mathrm{s}^{-1}$ for orth-MoVO in ZIBs. However, the capacitor-type contribution is only $54.6 \%$ even at $5 \mathrm{mV} \mathrm{s}^{-1}$ for tetra-MoVO due to the lack of seven- and six-member rings. Apparently, the orthMoVO shows the small charge-transfer resistance at the open- circuit potential, indicating the favorable electrochemical kinetics in ZIBs (Fig. S10).

In-situ XRD was carried out to clarify the crystal structure evolution of the orth-MoVO during the $\mathrm{Zn}^{2+}$ insertion/extraction process. Fig. 3a shows the detailed pseudo-colouring XRD patterns evolution when the orth-MoVO undergoes a discharge/ charge process (Fig. S11). The XRD pattern of the prepared cathode is similar to that of the pristine orth-MoVO. During the $\mathrm{Zn}^{2+}$ insertion process, the diffraction peaks at $22.3^{\circ}$ and $26.7^{\circ}$ slightly moved toward a higher degree, while the peaks at $7.0^{\circ}$, $8.2^{\circ}, 9.4^{\circ}, 11.2^{\circ}, 24.2^{\circ}, 27.1^{\circ}, 27.4^{\circ}, 27.6^{\circ}, 28.6^{\circ}$, and $29.6^{\circ}$ shifted toward lower degrees. Moreover, the peaks at $27.4^{\circ}$ and $27.6^{\circ}$ merged together. The peaks at $7.0^{\circ}, 8.2^{\circ}, 9.4^{\circ}$, and $22.3^{\circ}$ are attributed to the (020), (120), (210), and (001) crystal planes. These results indicate that the lattice space of $(020)$ increases, while that of (001) decreases during the $\mathrm{Zn}^{2+}$ insertion process. During the $\mathrm{Zn}^{2+}$ extraction process, all peaks approximately revert to the pristine state, which indicates excellent reversibility of the phase structure. The peak at about $33^{\circ}$, which is ascribed to $\mathrm{Zn}_{x} \mathrm{TOf}_{y}(\mathrm{OH})_{2 x-y} \cdot n \mathrm{H}_{2} \mathrm{O}$, appears and gradually increases during the discharge process, and then disappears in the charge process (Fig. S11c). This phenomenon further confirms the reversible Zn-based precipitate/dissolution. According to the reports $[4,10,53]$, the $\mathrm{Zn}_{x} \mathrm{TOF}_{y}(\mathrm{OH})_{2 x-y} \cdot n \mathrm{H}_{2} \mathrm{O}$ precipitate occurs on oxide-based electrodes during the electrochemical processes of aqueous ZIBs when the electrolyte is composed of $\mathrm{Zn}\left(\mathrm{CF}_{3} \mathrm{SO}_{3}\right)_{2}$. The $\mathrm{Zn}$-based precipitate reversibly appears in the discharge process and disappears in the subsequent charge 

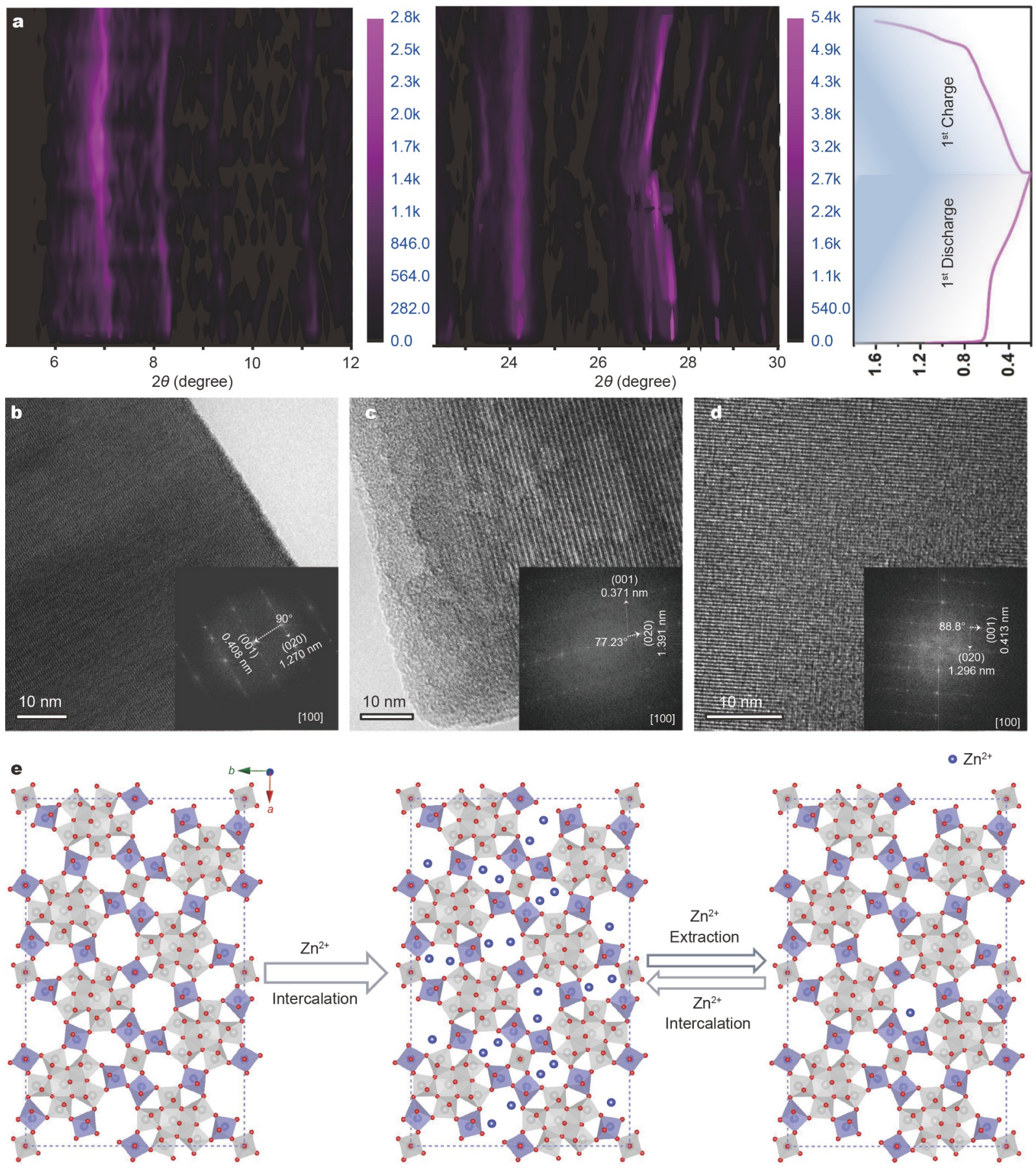

Figure 3 (a, b) Two-dimensional (2D) pseudo-color in-situ XRD pattern evolutions of orth-MoVO at the first discharge/charge process. HR-TEM image of the orth-MoVO at (b) the pristine, (c) discharged- $0.20 \mathrm{~V}$, and (d) charged-1.60 V. The inset is the corresponding FFT patterns. (e) Schematic illustration of the $\mathrm{Zn}^{2+}$ insertion/extraction for orth-MoVO.

process. In addition, the precipitation/dissolution phenomenon could permanently maintain in the weakly acidic $\mathrm{Zn}\left(\mathrm{CF}_{3} \mathrm{SO}_{3}\right)_{2}$ electrolyte. In-situ FT-IR was conducted (Fig. S12). The peak at $901 \mathrm{~cm}^{-1}$ exhibited a red-shift while the peak at $937 \mathrm{~cm}^{-1}$ exhibited a blue shift during the $\mathrm{Zn}^{2+}$ insertion process. After the extraction of $\mathrm{Zn}^{2+}$, the two peaks merged at $925 \mathrm{~cm}^{-1}$. These two peaks are considered to have been induced by the $\mathrm{V}-\mathrm{O}$ and Mo-O vibrations, which indicate that $\mathrm{Zn}^{2+}$ penetrates into the tunnels and coordinates with the $\mathrm{O}$ atoms. Additionally, a portion of $\mathrm{Zn}^{2+}$ remain in tunnels after the extraction process, and act as pillars for stabilizing the orth-MoVO. The EXAFS ensues, which indicates bond variations at different discharge/ charge stages. Fig. S13 shows the K-edge fast Fourier transform (FFT) function spectra of Mo, V, and Zn. After a full discharge/ charge process, the first dominant peaks of Mo and V slightly increased, and there were approximately no changes for $\mathrm{Zn}$.

XPS was performed to further demonstrate the changes of Mo, $\mathrm{V}$, and $\mathrm{C}$ during the discharge/charge process (Fig. S14). The 
XPS results indicated that $\mathrm{Zn}^{2+}$ underwent an insertion/extraction process, which is consistent with the EDS results presented in Fig. S15. The XPS and EDS analyses further revealed that the $\mathrm{Zn}^{2+}$ extraction process was not completely reversible in the first cycle. The TEM image of the orth-MoVO morphology under $0.20 \mathrm{~V}$ (Fig. S16b) shows a precipitation layer on the surface. This precipitation layer decomposed during the charging process (Fig. S16c). As shown in Fig. S17, the voltage of the orth-MoVO cathode remained stable below $0.25 \mathrm{~V}$ after the discharge process. However, the voltage sharply jumped to about $0.60 \mathrm{~V}$ after dipping in $\mathrm{HCl}$, which may be induced by the dissolution of the precipitation layer. According to the storage mechanism, $\mathrm{Zn}^{2+}$ entered into the tunnel and generated precipitation layer in the discharge process. The zinc contents calculated from the XPS data were $22.62 \%$ at $0.20 \mathrm{~V}$ and $1.55 \%$ at $1.60 \mathrm{~V}$, while those from the EDS data were $2 \%$ and almost negligible, respectively. Subsequently, HR-TEM was employed to track the structural transfer of the orth-MoVO during the GCD process. The HRTEM image of the orth-MoVO in Fig. $3 \mathrm{~b}$ and the corresponding FFT pattern in the [100] zone axis reveal a crystalline structure, which is in agreement with the results of scanning TEM (STEM, Fig. S18). After the orth-MoVO was discharged to $0.20 \mathrm{~V}$, the insertion of $\mathrm{Zn}^{2+}$ resulted in crystalline transformation (Fig. 3c). The lattice space of (001) decreased from 0.408 to $0.371 \mathrm{~nm}$, while the lattice space of (020) increased from 1.270 to $1.391 \mathrm{~nm}$. This phenomenon is in agreement with the in-situ XRD analysis results. The angle between (010) and (001) became $77.23^{\circ}$ (Fig. 3c), and then returned to $88.8^{\circ}$ after the orth-MoVO was charged to $1.60 \mathrm{~V}$ (Fig. $3 \mathrm{~d}$ ). Additionally, the lattice spaces of (001) and (020) underwent reversible changes during the charging process. Fig. S19 shows the Rietveld-refined XRD of the orth-MoVO at $0.20 \mathrm{~V}$ and the corresponding atomic structure in the [001] direction. It is proposed that $\mathrm{Zn}^{2+}$ inserted into the six- and seven-member rings of the orth-MoVO. The $\mathrm{Zn}^{2+}$ storage mechanism is illustrated in Fig. $3 \mathrm{e}$ according to the abovementioned results. In the discharge process, $\mathrm{Zn}^{2+}$ entered into the orth-MoVO tunnels. Then, part of $\mathrm{Zn}^{2+}$ remained in the tunnels to stabilize the orth-MoVO after the $1^{\text {st }}$ charge process. Thereafter, the $\mathrm{Zn}^{2+}$ ions can be inserted and extracted reversibly into/from the orth-MoVO in the subsequent GCD processes.

With consideration of the most favourable path of $\mathrm{Zn}^{2+}$ diffusion, the possible adsorption sites on the oxygen atoms of $\mathrm{MoO}_{6}$ and/or $\mathrm{VO}_{6}$ in seven-, six- and five-member $\mathrm{MO}_{6}$ units were considered. The DFT calculation was carried out to theoretically evaluate the adsorption properties of $\mathrm{Zn}^{2+}$. The formation energies of $\mathrm{Zn}^{2+}$ ions embedded into the three investigated systems were employed. The porous channel consisting of heptagonal and hexagonal $\mathrm{MO}_{6}$ clusters (channel) was selected for the orth- and tri-MoVO, while the pentagonal channel for tetra-MoVO, with the consideration of the most favourable path of $\mathrm{Zn}^{2+}$ diffusion. Additionally, different possible adsorption sites on the oxygen atoms around the porous channels were considered, and the one with the strongest adsorption was chosen as the most stable adsorption site. According to the calculation results in Fig. 4a and Fig. S20, the $\mathrm{Zn}$ atoms are prone to entering the hepta-member channel with two $\mathrm{Zn}^{2+}$ ions simultaneously inside, which is consistent with the experimental estimations. The 11 diffusion pathways were considered to give the optimal model of $\mathrm{Zn}^{2+}$ diffusion. In Fig. $4 \mathrm{~b}$, $\mathrm{Zn}^{2+}$ tends to alternately enter the hepta- and hexa-member channels of orth-MoVO, both of which allow for two- $\mathrm{Zn}^{2+}$ insertions. The system becomes unstable if the third $\mathrm{Zn}^{2+}$ entered the hepta- and hexa-member channels. Consistent with Fig. S17, about one third of the discharge capacity is ascribed to the four- $\mathrm{Zn}^{2+}$ insertion process, whereas the other two thirds discharge capacity is obtained from the precipitation reaction on
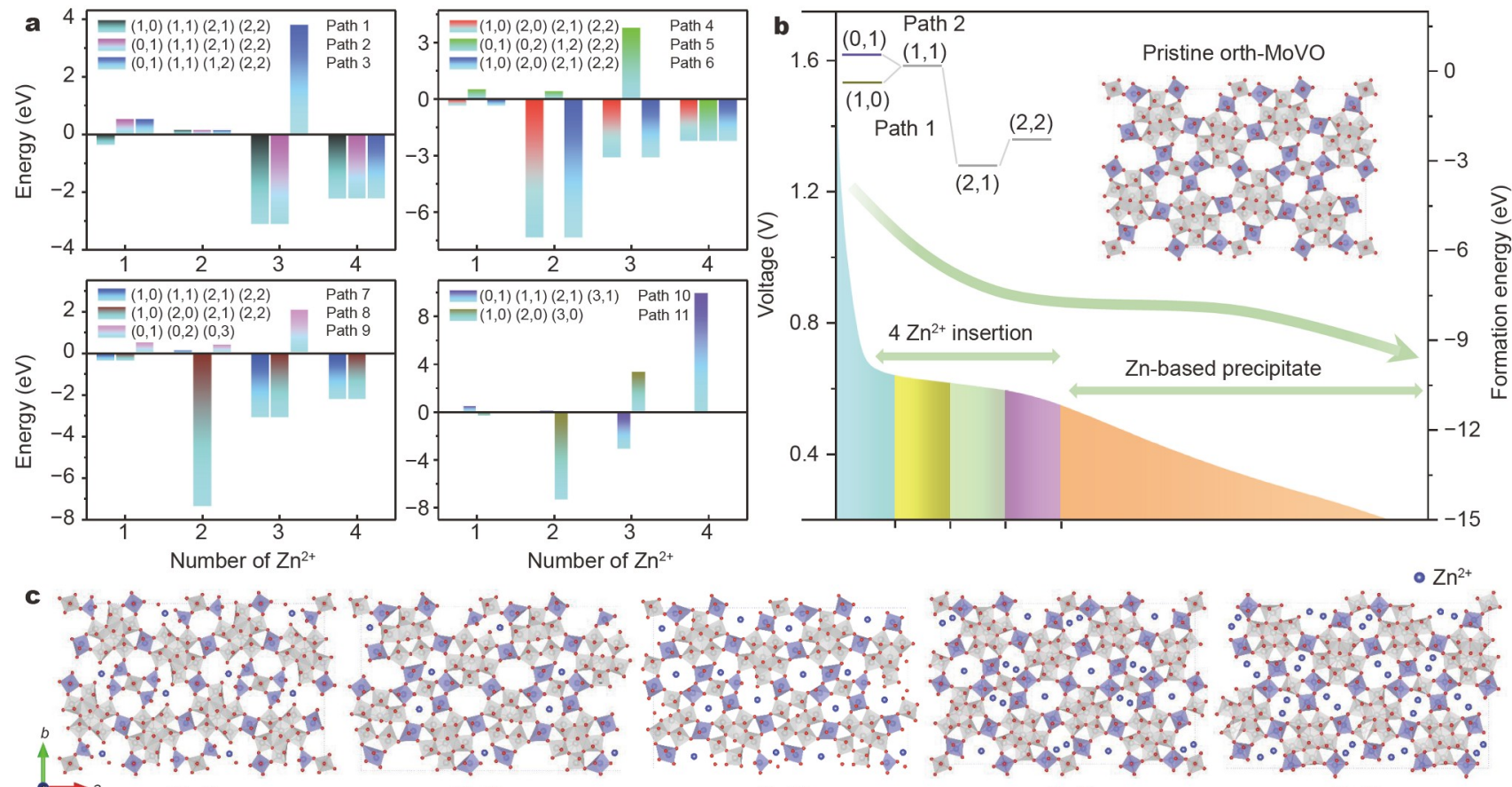

$(0,1)$

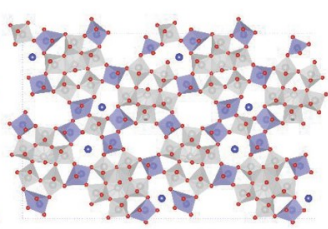

$(1,0)$

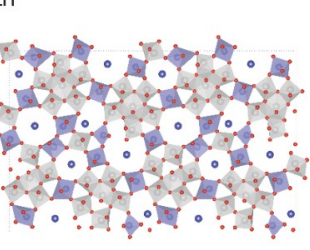

$(1,1)$

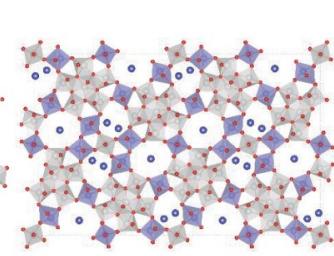

$(2,1)$

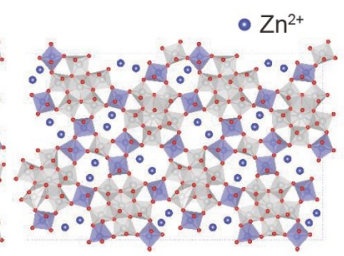

$(2,2)$

Figure 4 (a) The adsorption energy evolution for the possible zincation process of orth-MoVO; for $(x, y)$, $x$ and $y$ represent the number of zinc ions in sevenand six-member rings, respectively; (b) the two most possible zincation pathways for orth-MoVO; (c) the corresponding atomic structure in the [001] direction. 
the surface of the orth-MoVO. Fig. 4c and Fig. S21 show the optimal atomic model after accommodating $\mathrm{Zn}^{2+}$ for orthMoVO. However, the situation is different for tri-MoVO. In Figs S22 and S23, the system is unstable for $\mathrm{Zn}^{2+}$ insertion in hepta- or hexa-member channels. As shown in Fig. S24, the only possible channel to accommodate $\mathrm{Zn}^{2+}$ is the penta-member channel in tetra-MoVO. Considering the channel density and the structural stability, the orth-MoVO exhibits the maximal capacity accommodation and highest kinetic properties for ZIBs.

\section{CONCLUSION}

In summary, a series of Mo- $\mathrm{V}$ oxides with diverse phase structures were precisely constructed. The obtained orth-, tri-, and tetra-MoVO were composed of various tunnels, which provided alternative paths for $\mathrm{Zn}^{2+}$ diffusion as the cathodes in ZIBs. Consequently, the orth-MoVO phase achieved the highest specific capacity and best cyclic stability. The structural and elemental evolutions were also discussed in detail. According to the analyses, the outstanding $\mathrm{Zn}^{2+}$ storage ability is attributed to the numerous six- and seven-member ring tunnels in the orthMoVO phase. Additionally, the orthorhombic phase structure provides a stable framework for the alternative zinc insertion process, which results in a superior cyclic stability. Both the phase and tunnel structures are responsible for the outstanding electrochemical behaviors. In conclusion, the proposed phase engineering strategy provides a new approach for designing cathodes that can be effectively incorporated in ZIBs.

\section{Received 21 July 2021; accepted 22 September 2021;} published online 12 November 2021

1 Fang G, Zhou J, Pan A, et al. Recent advances in aqueous zinc-ion batteries. ACS Energy Lett, 2018, 3: 2480-2501

2 Chao D, Zhu CR, Song M, et al. A high-rate and stable quasi-solid-state zinc-ion battery with novel 2D layered zinc orthovanadate array. Adv Mater, 2018, 30: 1803181

3 Cai $\mathrm{Y}$, Liu F, Luo Z, et al. Pilotaxitic $\mathrm{Na}_{1.1} \mathrm{~V}_{3} \mathrm{O}_{7.9}$ nanoribbons/graphene as high-performance sodium ion battery and aqueous zinc ion battery cathode. Energy Storage Mater, 2018, 13: 168-174

4 Zhu K, Wu T, Huang K. A high capacity bilayer cathode for aqueous Zn-ion batteries. ACS Nano, 2019, 13: 14447-14458

$5 \mathrm{Xu} \mathrm{X}$, Xiong F, Meng J, et al. Vanadium-based nanomaterials: A promising family for emerging metal-ion batteries. Adv Funct Mater, 2020, 30: 1904398

6 Zhong WW, Huang J, Liang S, et al. New prelithiated $\mathrm{V}_{2} \mathrm{O}_{5}$ superstructure for lithium-ion batteries with long cycle life and high power. ACS Energy Lett, 2020, 5: 31-38

7 Liu Y, Li Q, Ma K, et al. Graphene oxide wrapped $\mathrm{CuV}_{2} \mathrm{O}_{6}$ nanobelts as high-capacity and long-life cathode materials of aqueous zinc-ion batteries. ACS Nano, 2019, 13: 12081-12089

8 Nam KW, Park SS, Dos Reis R, et al. Conductive 2D metal-organic framework for high-performance cathodes in aqueous rechargeable zinc batteries. Nat Commun, 2019, 10: 4948

9 Xing Z, Wang S, Yu A, et al. Aqueous intercalation-type electrode materials for grid-level energy storage: Beyond the limits of lithium and sodium. Nano Energy, 2018, 50: 229-244

10 Wang L, Huang KW, Chen J, et al. Ultralong cycle stability of aqueous zinc-ion batteries with zinc vanadium oxide cathodes. Sci Adv, 2019, 5: eaax 4279

11 Ma L, Chen S, Long C, et al. Achieving high-voltage and high-capacity aqueous rechargeable zinc ion battery by incorporating two-species redox reaction. Adv Energy Mater, 2019, 9: 1902446

12 Xia C, Guo J, Li P, et al. Highly stable aqueous zinc-ion storage using a layered calcium vanadium oxide bronze cathode. Angew Chem Int Ed,
2018, 57: 3943-3948

13 Fu Y, Wei Q, Zhang G, et al. High-performance reversible aqueous $\mathrm{Zn}$ ion battery based on porous $\mathrm{MnO}_{x}$ nanorods coated by MOF-derived N-doped carbon. Adv Energy Mater, 2018, 8: 1801445

14 Hu P, Zou Z, Sun X, et al. Uncovering the potential of M1-site-activated NASICON cathodes for Zn-ion batteries. Adv Mater, 2020, 32 1907526

15 Kim SJ, Tang CR, Singh G, et al. New insights into the reaction mechanism of sodium vanadate for an aqueous $\mathrm{Zn}$ ion battery. Chem Mater, 2020, 32: 2053-2060

16 Zheng J, Liu C, Tian M, et al. Fast and reversible zinc ion intercalation in Al-ion modified hydrated vanadate. Nano Energy, 2020, 70: 104519

17 Zhang Y, Wan F, Huang S, et al. A chemically self-charging aqueous zinc-ion battery. Nat Commun, 2020, 11: 2199

18 Shi HY, Sun X. Interlayer engineering of layered cathode materials for advanced $\mathrm{Zn}$ storage. Chem, 2020, 6: 817-819

19 Tang B, Shan L, Liang S, et al. Issues and opportunities facing aqueous zinc-ion batteries. Energy Environ Sci, 2019, 12: 3288-3304

20 Liao M, Wang J, Ye L, et al. Extraction of oxygen anions from vanadium oxide making deeply cyclable aqueous zinc ion battery. Angew Chem Ed Int, 2019, 59: 2273-2278

21 Javed MS, Lei $\mathrm{H}$, Wang $\mathrm{Z}$, et al. 2D $\mathrm{V}_{2} \mathrm{O}_{5}$ nanosheets as a binder-free high-energy cathode for ultrafast aqueous and flexible $\mathrm{Zn}$-ion batteries. Nano Energy, 2020, 70: 104573

$22 \mathrm{Xu} \mathrm{W}$, Sun C, Wang N, et al. Sn stabilized pyrovanadate structure rearrangement for zinc ion battery. Nano Energy, 2021, 81: 105584

23 He P, Zhang G, Liao X, et al. Sodium ion stabilized vanadium oxide nanowire cathode for high-performance zinc-ion batteries. Adv Energy Mater, 2018, 8: 1702463

24 Guo X, Fang G, Zhang W, et al. Mechanistic insights of $\mathrm{Zn}^{2+}$ storage in sodium vanadates. Adv Energy Mater, 2018, 8: 1801819

25 Wang $\mathrm{F}, \mathrm{Hu} \mathrm{E}$, Sun $\mathrm{W}$, et al. A rechargeable aqueous $\mathrm{Zn}^{2+}$-battery with high power density and a long cycle-life. Energy Environ Sci, 2018, 11: 3168-3175

26 Deng W, Zhou Z, Li Y, et al. High-capacity layered magnesium vanadate with concentrated gel electrolyte toward high-performance and wide-temperature zinc-ion battery. ACS Nano, 2020, 14: 15776-15785

27 Guo S, Liang S, Zhang B, et al. Cathode interfacial layer formation via in situ electrochemically charging in aqueous zinc-ion battery. ACS Nano, 2019, 13: 13456-13464

28 Guo J, Ming J, Lei Y, et al. Artificial solid electrolyte interphase for suppressing surface reactions and cathode dissolution in aqueous zinc ion batteries. ACS Energy Lett, 2019, 4: 2776-2781

29 Bin D, Huo W, Yuan Y, et al. Organic-inorganic-induced polymer intercalation into layered composites for aqueous zinc-ion battery. Chem, 2020, 6: 968-984

30 Wang X, Xi B, Ma X, et al. Boosting zinc-ion storage capability by effectively suppressing vanadium dissolution based on robust layered barium vanadate. Nano Lett, 2020, 20: 2899-2906

31 Fang G, Liang S, Chen Z, et al. Simultaneous cationic and anionic redox reactions mechanism enabling high-rate long-life aqueous zinc-ion battery. Adv Funct Mater, 2019, 29: 1905267

32 Pyrz WD, Blom DA, Sadakane M, et al. Atomic-level imaging of Mo-V$O$ complex oxide phase intergrowth, grain boundaries, and defects using HAADF-STEM. Proc Natl Acad Sci U S A, 2010, 107: 6152-6157

33 Wang PF, You Y, Yin YX, et al. Layered oxide cathodes for sodium-ion batteries: Phase transition, air stability, and performance. Adv Energy Mater, 2018, 8: 1701912

34 Wang PF, Yao HR, Liu XY, et al. Ti-substituted $\mathrm{NaNi}_{0.5} \mathrm{Mn}_{0.5-x} \mathrm{Ti}_{x} \mathrm{O}_{2}$ cathodes with reversible O3-P3 phase transition for high-performance sodium-ion batteries. Adv Mater, 2017, 29: 1700210

35 Song J, Zhu C, Xu BZ, et al. Bimetallic cobalt-based phosphide zeolitic imidazolate framework: $\mathrm{CoP}_{x}$ phase-dependent electrical conductivity and hydrogen atom adsorption energy for efficient overall water splitting. Adv Energy Mater, 2017, 7: 1601555

$36 \mathrm{Gu} \mathrm{M}$, Belharouak I, Zheng J, et al. Formation of the spinel phase in the layered composite cathode used in Li-ion batteries. ACS Nano, 2013, 7: $760-767$

37 Jiang S, Zhou W, Niu Y, et al. Phase transition of a cobalt-free per- 
ovskite as a high-performance cathode for intermediate-temperature solid oxide fuel cells. ChemSusChem, 2012, 5: 2023-2031

38 Zhao D, Qin J, Zheng L, et al. Amorphous vanadium oxide/molybdenum oxide hybrid with three-dimensional ordered hierarchically porous structure as a high-performance Li-ion battery anode. Chem Mater, 2016, 28: 4180-4190

$39 \mathrm{Qu}$ G, Zhao L, Jia S, et al. In situ facile bubble-templated fabrication of new-type urchin-like ( $\mathrm{Li}, \mathrm{Mo})$-doped $\mathrm{Li}_{x}\left(\mathrm{Mo}_{0.3} \mathrm{~V}_{0.7}\right)_{2} \mathrm{O}_{5}$ for $\mathrm{Zn}^{2+}$ storage. J Mater Chem A, 2017, 5: 18253-18260

40 Sadakane M, Watanabe N, Katou T, et al. Crystalline $\mathrm{Mo}_{3} \mathrm{VO}_{x}$ mixedmetal-oxide catalyst with trigonal symmetry. Angew Chem Int Ed, 2007, 46: 1493-1496

41 Sadakane M, Kodato K, Kuranishi T, et al. Molybdenum-vanadiumbased molecular sieves with microchannels of seven-membered rings of corner-sharing metal oxide octahedra. Angew Chem Int Ed, 2008, 47: 2493-2496

42 Ishikawa S, Ueda W. Microporous crystalline Mo-V mixed oxides for selective oxidations. Catal Sci Technol, 2016, 6: 617-629

43 Perdew JP, Burke K, Ernzerhof M. Generalized gradient approximation made simple. Phys Rev Lett, 1996, 77: 3865-3868

44 Kresse G, Furthmüller J. Efficiency of ab-initio total energy calculations for metals and semiconductors using a plane-wave basis set. Comput Mater Sci, 1996, 6: 15-50

45 Kresse G, Hafner J. Ab initio molecular dynamics for liquid metals. Phys Rev B, 1993, 47: 558-561

46 Kresse G, Hafner J. Ab initio molecular-dynamics simulation of the liquid-metal-amorphous-semiconductor transition in germanium. Phys Rev B, 1994, 49: 14251-14269

47 Kresse G, Furthmüller J. Efficient iterative schemes for ab initio totalenergy calculations using a plane-wave basis set. Phys Rev B, 1996, 54: 11169-11186

48 Monkhorst HJ, Pack JD. Special points for brillouin-zone integrations. Phys Rev B, 1976, 13: 5188-5192

49 Pyrz WD, Blom DA, Sadakane M, et al. Atomic-scale investigation of two-component MoVO complex oxide catalysts using aberration-corrected high-angle annular dark-field imaging. Chem Mater, 2010, 22: 2033-2040

50 Pan $\mathrm{H}$, Shao $\mathrm{Y}$, Yan $\mathrm{P}$, et al. Reversible aqueous zinc/manganese oxide energy storage from conversion reactions. Nat Energy, 2016, 1: 16039

51 Huang J, Wang Z, Hou M, et al. Polyaniline-intercalated manganese dioxide nanolayers as a high-performance cathode material for an aqueous zinc-ion battery. Nat Commun, 2018, 9: 2906

52 Pyrz WD, Blom DA, Shiju NR, et al. Using aberration-corrected STEM imaging to explore chemical and structural variations in the M1 phase of the MoVNbTeO oxidation catalyst. J Phys Chem C, 2008, 112: 10043-10049

53 Luo $\mathrm{H}$, Wang B, Wu F, et al. Synergistic nanostructure and heterointerface design propelled ultra-efficient in-situ self-transformation of zinc-ion battery cathodes with favorable kinetics. Nano Energy, 2021, 81: 105601

Acknowledgements This work was supported by Guangdong Natural Science Foundation (2019A1515010675), the Science and Technology Project of Shenzhen (JCYJ20180305125106329 and KQJSCX20180328094001794). Prof. Su C thanks the support from Guangdong Special Support Program. The authors wish to acknowledge the assistance in HR-TEM observation received from the Electron Microscope Center and Instrumental Analysis Center of Shenzhen University.

Author contributions Qu G designed and conducted the experiment, and wrote the manuscript; Qiu C provided the samples; Wang J performed the theoretical calculation; Tan J performed some data analysis; Jia S performed the STEM measurement; Chen $\mathrm{Z}$ and Rueff J performed the EXAFS measurement; Zheng $\mathrm{G}$ and Su C provided helpful suggestions; Tian B designed this study, analysed the data and revised the paper. All authors contributed to the general discussion.

Conflict of interest

The authors declare that they have no conflict of interest.

Supplementary information Experimental details and supporting data are available in the online version of the paper.

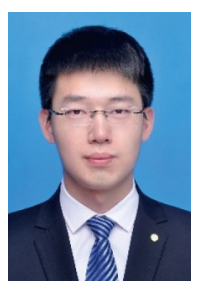

Gan Qu received his bachelor degree from Henan University in 2011, master degree from Wuhan University in 2013 under the supervision of Prof. Jiming Hu, and doctor degree from Wuhan University in 2017 under the supervision of Prof. Jianbo Wang. Then, he was a postdoctoral research fellow at Shenzhen University from 2017 to 2019. $\mathrm{He}$ is currently a lecturer at the School of Material Science \& Engineering at Zhengzhou University. His research focuses on lithium-sulfur batteries, aqueous rechargeable batteries, and supercapacitors.

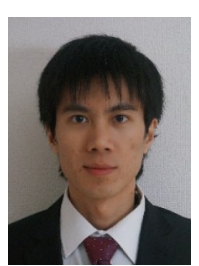

Chuntian Qiu received his BS (2009) and MA (2012) degrees from the Department of Chemistry at Sichuan University, and $\mathrm{PhD}$ degree (2015) from the Catalysis Research Center at Hokkaido University. After that he worked as a postdoctor (2016-2018) and associate research fellow (2018-) at the International Collaborative Laboratory of 2D Materials for Optoelectronics Science and Technology (ICL-2D MOST), Shenzhen University. His current interests focus on the design of materials for photo/electro-catalysis and energy-related applications.

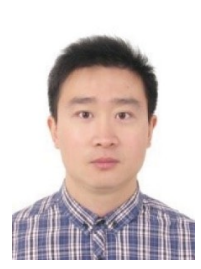

Bingbing Tian received his bachelor degree from Zhengzhou University (China) in 2008, master degree from South China University of Technology (China) in 2011 under the supervision of Prof. Haihui Wang, and doctor degree from the Université Pierre et Marie Curie (France) in 2014 under the supervision of Prof. Philippe Marcus. Then he was a postdoctoral research fellow at the National University of Singapore from 2015 to 2017. He is currently an associate professor at the Institute of Microscale Optoelectronics at Shenzhen University. His research activities are focused on energy storage devices including metal ion batteries, lithium-sulfur batteries and all-solid-state batteries.

\section{基于分子篮结构的钿钒氧化物相工程在锌离子电池 中的研究}

曲 ${ }^{2 \dagger}$, 邱春天 ${ }^{1 \dagger}$, 王俊 ${ }^{1}$, 谭杰文 ${ }^{1}$, 贾双风 ${ }^{4}$, 陈哲生 ${ }^{5}$,

Jean-Pascal Rueff ${ }^{5,6}$, Wesley Guangyuan Zheng ${ }^{3}$, 苏陈良 ${ }^{1}$, 田冰冰 ${ }^{1 *}$

摘要 随着大规模储能需求的不断增加，水性锌离子电池在世界范围 内引起了越来越多的关注. 然而, 基于锌离子存储的宿主材料有限, 严 重地阻碍了锌离子电池的商业化应用. 基于此, 本论文精确地构建了一 系列相结构(正交、三方和四方晶系)的钿钒氧化物, 研究了该锄钒氧化 物电极材料在锌离子电池中的储锌性能. 一系列开放的框架和隧道结 构有利于锌离子的扩散动力学. 通过相工程优化, 正交晶系的钿钒氧化 物电极材料的比容量能够达到约 $400 \mathrm{~mA} \mathrm{~h} \mathrm{~g}^{-1}$, 循环稳定性达到了 1000 次. 正交晶系的钿钒氧化物相中具有大量的六元和七元环结构, 在锌离 子的可逆嵌入/脱出反应方面发挥了至关重要的作用. 本文提出的相工 程策略为锌离子电池中正极材料的设计提供了一种新方法. 